Now, since in Iceland spar the optic axis makes an angle of very nearly $45^{\circ}$ (strictly, $44^{\circ} 36^{\prime}$ ) with the natural faces of the rhombohedron, all that is required is to obtain an even cleavage-plate of the spar, abont $2 \mathrm{~cm}$. $\times 1 \mathrm{~cm}$. and about $2 \mathrm{~mm}$. thick, to brea's it in half, to turn one of the pieces round in a plane parallel to its surfaces through an angle of $180^{\prime \prime}$ from its position when broken off, and to cement it on the other piece in this position with Canada balsam or dammar.

Then, on placing the combination in a polariscope (for instance, laying it on the eye-lens of a microscope with analyser just above it) the series of ellipses will be well seen. Sodium light, e.g. that from a Bunsen burner with a bead of sodium carbonatc held in the flame, must be used.

Prof. Ohm refers to a paper by Langberg (which I have not been able to get a sight of) in which the occurrence and form of these bands were predicted from theory ; so that the case resembles those of Airy's spirals and Hamilton's conical refraction.

A pair of plates with surfaces making an angle of $70^{\circ}$ (or more) with the optic axis also show these ellipses; and perhaps more instructively, since with such plates it is easy to trace the origin of the bands in the coalescence of portions of the circular isochromatic bands of high order which surround the optic axis in each plate.

Those who have a pair of Savart's plates mounted so that one can rotate over the other, will find it most interesting and instructive to watch (in monochromatic light) the changes in form and character of the interference-bands as the azimuth of one of the plates is gradually altered.

Eton College

H. G. MADAN

\section{CONTINUOUS AUTOMATIC BRAKES}

THE returns of the Railway Department of the Board of Trade serve as an excellent index to the defects in the management and working of the railway systcm in this country, the defects being brought to light during the investigations of the trivial casualties and disastrous accidents which take place, and inquired into by the experienced inspectors of the Board of Trade.

It is evident that by far the greater number of accidents seem to have been caused by the trains not being fitted with a really good brake, and in consequence being unable to stop quickly in cases of emergency. Some even have been caused by the brake itself failing to "go on "when required, caused either by some defect in the brake mechanism, or the design of the brake itself has been bad, giving the enginc-driver a false sense of security, and leading the train with its living load into unnecessary danger.

It is a pity the railway companies do not pay more attention to the conditions laid down by the Board of Trade with regard to continuous brakes, stating the qualities the brake ought to possess, for it is evident the Board does not wish the adoption of any particular patentee's brake, but a brake which includes to the fullest extent the conditions laid down. It so happens that the Westinghouse automatic brake answers the conditions better than any other, and therefore the Board is anxious to see it in general use, not because an exinspector of the Board happens to be the chairman of the English Westinghouse Brake Company, as the secretary of one English railway seems to imagine, but because it is the best brake.

In an extract from the Board of Trade returns on continuous bra'zes for the half year ending June 30 , published by the Vacuum Brake Company, we find the Westinghouse automatic credited with 397 faults for a mileage of $15,506,447$.

We think it may be truly stated that the Westinghouse automatic has not had fair play with some of the companies having it partially in use, its failures having been carefully reported, while any failure of their own special brake, not having any serious consequences, has been looked over.

Take for instance the returns sent in by the Midland Company. Here the Westinghouse automatic has failed thirty-scven times for a mileage of $37+, 390$, or one fault for cvery I0,118 miles, while the Midland automatic vacuum has six failures reported for a mileage of $5,245,573$, or one fault for every 874,262 miles run. On the other hand we have the London, Brighton, and South Coast Railway using the Westinghouse automatic on the whole of their trains; they report seventy-four failures for a mileage of $3,122,5 \mathrm{ro}$, or one fault for every 42, I 96 miles run.

Why should the Westinghouse automatic run four times as many miles per failure on the Brighton line than on the Midland? The reason is not far to seek; on the Brighton line the Westinghouse automatic is properly looked after, and kept in good repair, while on the Midland it has to stand back and give place to the vacuum automatic, the Company's brake.

The automatic vacuum brake in use on the Midland Railway has, as its name implics, the pressure of the atmosphere opposed to a partial vacuum for its motive

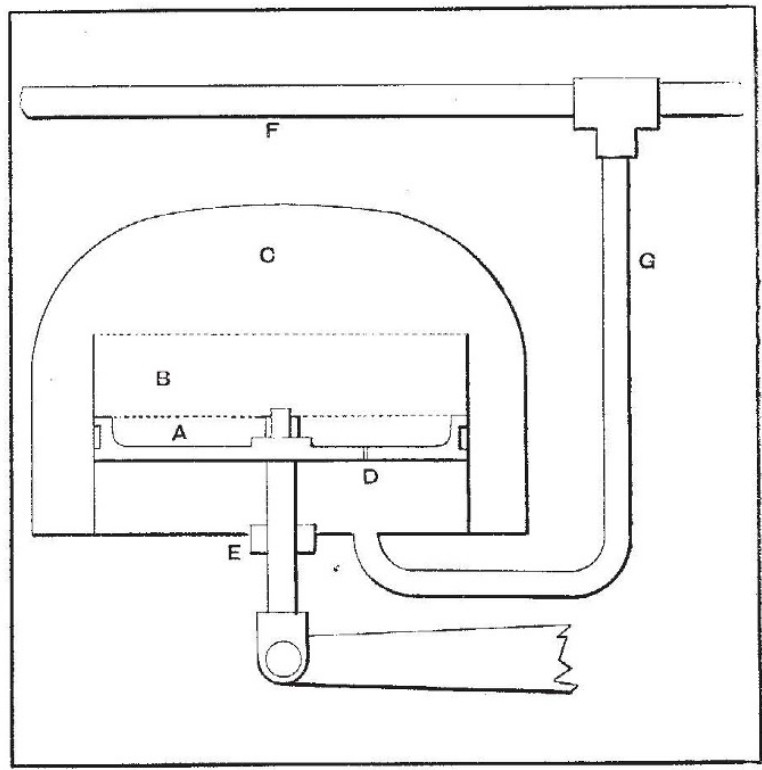

power, the vacuum being created by means of an ejector on the engine, connected to every vehicle on the train by means of a continuous pipe, having flexible pipes and couplings between the vehicles. To maintain the vacuum throughout the train against leakage, there is a small ejector continually in use on the engine.

Coupled to the continuous pipe on each vehicle is the automatic brake cylinder and reservoir peculiar to the Midland automatic brake, the piston being connected by means of levers and rods to the brake-blocks. The illustration gives a good idea of the general construction of the brake-cylinder and its connections, the arrangement being as follows:- The brake-cylinder $\mathrm{B}$ is placed inside the reservoir $\mathrm{c}$, the piston $\mathrm{A}$ working air-tight in the cylinder ; the piston-rod passing through the bottom of the cylinder by means of a gland, $\mathrm{E}$, having a flexible packir: ring. so arranged that when the piston is at the bottom of the cylinder it comes in contact with the packing ring, making an air-tight joint; but when the piston moves upwards, lcaving the packing ring, air is able to pass through the gland into the lower part of the brake-cylinder. The continuous pipe $F$ is connected by the branch pipe $c$ to the lower part of the brake-cylinder. 
Through the piston there is a small hole, $\mathrm{D}$, called the leak-hole, his being one of the main features of the brake, the mode of action of which is as follows:A vacuum is created in the continuous pipe by means of the ejector on the engine, the air being drawn from below the pistons in the brake-cylinder by the branch connections; the air in the reservoir $\mathrm{C}$ leaks through the leak hole $D$, and after a short time there is an equal vacuum above and below the pistons. The brake is now charged, and in its usual condition when the train is running, the vacuum being maintained against accidental leakage by the continual use of the small ejector.

To apply the brake, air is admitted into the continuous pipe, destroying the partial vacuum, and, increasing the pressure below the pistons, causes them to rise, breaking at the same time the air-tight joint made by the piston against the packing ring, thereby admitting air direct, through the gland, into the lower part of the brake-cylinder, causing the application of the brakes to be nearly instantaneous. It will be observed that, directly the piston is forced up by the atmospheric pressure, the vacuum in the reservoir will gradually be destroyed by air passing through the leak-hole, in fact after less than two minutes it has leaked itself entirely off. It is also evident that it cannot be instantly charged, for the vacuum in the reservoir has to be created through the leak-hole.

It is stated by some that the Midland automatic vacuum answers all the Board of Trade conditions, and is therefore to be regarded as an effective serviceable automatic brake. On studying the reports in the returns, and the failures of this brake as reported in the technical papers, we see how absurd the claim to efficiency becomes. For example, the brake cannot be applied quickly several times in succession; when applied even once, the effective brake power has all vanished in two minutes, thus getting the doubtful name of the "two-minute leak-off brake." Again, suppose a train became divided from any cause, when ascending a heavy gradient, the bra'ze should automatically apply itself, and remain applied until taken off by hand. What would the Midland automatic vacuum do under the above circumstances? Certainly the brake would apply itself, but in two minutes or less all the available brake power will have vanished, and, should the hand-brake in the rear van not prove powerful enough to hold the train on the bank, it will commence to run back.

Although the Midland Company have the automatic vacuum in general use, it is no criterion that the brake is satisfactory; we have only to add that the engines and tenders are fitted with an efficient steam brake, so that in entering stations, should the automatic vacuum fail, the steam brake is quite capable of stopping the train, only taking a little further distance to pull up in. At terminal stations sometimes this is very awkward, as the accident at the Liverpool Central Station, which happened some time ago, shows. Here the automatic vacuum brake failed, and the train ran into a brake-van standing by the stopblocks, doing considerable damage. Reports of failures of the Midland automatic vacuum may be seen almost weekly in the "Railway Matters" column of the Engineer, and we give, as an example taken at random, one reported in the issue for October I7:- "As it is not very likely to be elsewhere recorded, it may be here mentioned that on the Ioth inst. a twelve-coach Midland Scotch express ran clean through Bedford station before it was stopped, in consequence of the failure of the leak-off vacuum brake." Such failures are highly dangerous, and any brake with which they are likely to occur cannot be efficient, and therefore ought not to be trusted to stop trains at any important junction or station, and its use absolutely prohibited on approaching a terminal.

It may be interesting to have a short account of the Westinghouse automatic pressure brake, the worst fault of which, according to its opponents, is its efficiency in stopping trains should anything go wrong with the brake apparatus. The motive power of this brake is compressed air at a pressure of about 80 lbs. to Ioo lbs., compressed by an ingeniously constructed steam-pump on the engine, and stored in a main reservoir under the footplate; throughout the train runs a pipe, connected between the vehicles by means of flexible hose pipes and couplings. On each vehicle, including the engine, is placed a small reservoir, a triple valve, and a brake cylinder, with a piston connected by levers and rods to the brake blocks. On the engine is placed the driver's brake-valve for working the brake. The whole system of this brake lies entirely in the construction and action of the triple valve. When the brake is in use, the trainpipe and small reservoirs are charged with compressed air, the air passing through the triple valve in its passage from the train-pipe to the small reservoirs. On the airpressure being reduced, the triple valve opens a passage between the small reservoir and the brake-cylinder, thus allowing the compressed air stored to expand into the brake-cylinder, forcing out the piston, and applying the brake. To take the brake off, the converse happens: the pressure in the train-pipe is increased, the triple valve closing the passage between the small reservoir and the brake-cylinder, at the same time allowing the compressed air in the brake-cylinder to exhaust into the atmosphere, the small reservoir again being charged with compressed air from the train-pipe.

The triple valve consists of a small cylinder having a piston connected on the upper side to a small slide-valve working over two ports, arranged one about the other, the lower opening direct to the atmosphere, the upper connected by a pipe to the brake-cylinder. The slide-valve works in a small casing connected to the small reservoir ; the triple valve is connected to the train-pipe by a pipe opening into the lower part of the cylinder in which the small piston works. When the piston is at the top of the cylinder it opens a connection between its lower and upper side, thus allowing compressed air to pass round the piston into the casing in which the slide-valve works, then into the small reservoir. When in this position, the slide-valve has closed both ports to the compressed air in the casing, the port leading to the brake-cylinder being open, through the valve, to the lower or exhaust port.

On charging the train-pipe with compressed air it will be observed that the piston in the triple valve will be forced up, thus filling the small reservoir and triple valve with compressed air, but not the brake-cylinder; also that the pressure of air on both sides of the piston in the triple valve will be equal; on reducing the air-pressure in the train-pipe by a few pounds, the piston will naturally be forced down, by the greater pressure on the upper side moving the slide-valve and allowing a quantity of the compressed air in the small reservoir to enter the port leading to the brake-cylinder, and apply the brake.

The air expanding into the brake-cylinder will cause its pressure to be reduced, and therefore balance the piston in the triple valve. It is evident therefore that any small reduction of pressure in the train-pipe will cause a corresponding application of the brake, a reduction of the pressure by 25 lbs. being sufficient to put the brake hard on and skid every wheel.

The function of the driver's brake-valve is to work the brake-apparatus by varying the pressure of the air in the train-pipe. In the first position of the handle which works the valve, called the charging position, air from the main reservoir is able to go direct to the train-pipe, to charge or release the brake. On moving the handle through an angle of a few degrees into the feed-position, the connection between the main reservoir and the trainpipe is closcd, the compressed air having to pass through a pressure-reducing valve on its way to the train-pipe from the main reservoir to make up for any slight leakage which may occur.

It is important that the pressure of the air in the main 
reservoir should always be about 15 lbs. above that in the train-pipe, so that when the brakes are being relcased by increasing the pressure in the train-pipe direct from the main reservoir, the triplc valves are certain to act, on account of the extra 15 lbs. pressurc in the train-pipe above the pressure in the small reservoirs.

On moving the handle of the driver's valve further in the same direction, or into the position for applying the brakes, all connection between the main reservoir and the train-pipe is cut off, at the same time that the trainpipe is put in conncction with the atmosphere, through an exhaust port; by this means the pressure in the trainpipc can be reduced to any degree to apply the brakc. All brake-cylinders on vehicles arc fitted with a releasevalve, so that, should the brakc be applicd when the engine is not attached, the air can be discharged from the brake-cylinder, through the release-valve, by pulling a wire attached to the valve.

All vehicles now fitted with this brake have cocks at each end of the train-pipe, so that, should any change have to be made in the train, the coupling or uncoupling of vehicles is easily accomplished without the brake automatically applying itself.

It is casy to see that this brake is automatic in its action, for should the train-pipe or flexible couplings be injured by accident, or the train part into two or more portions, the compressed air will escape from the trainpipe, and the brake will apply itself. In all guards' vans is placed a cock in connection with the train-pipe, so that, should the guard observe anything wrong with the train, or receive a signal from a passenger, he can instantaneously apply the brake by opening the cock and discharging the air from the train-pipe.

The Westinghouse automatic brake is at present the only one which really includes all the qualities in the Board of Trade requirements for continuous brakes, and perhaps it will not be out of place to state the requirements of the Board of Trade.

(1) The brakes to be efficient in stopping trains, instantancous in their action, capable of being applied without difficulty by engine-drivers and guards.

(2) In cases of accident, to be instantancously selfacting.

(3) The brakes to be put on and taken off (with facility) on the engine and cvery vehicle of a train.

(4) The brakes to be used in daily working.

(5) The material employed to be of a durable character, so as to be easily maintained and kept in order.

On looking through the Board of Trade returns on continuous brakes for the six months ending June 30 , one sees that over two-thirds of the failures of the Westinghouse automatic are due to burst hosc pipes alone, and therefore not failures of the brake itself, but of faulty inspection and bad material. We would like to hear of experiments being made with a stronger and more durable material, so as to resist the destructive action of the oil and tallow, of which such a large quantity is used on railways. Could this improvement be effected, we are convinced the number of miles run per failure would immediately vastly increase, leaving the automatic vacuum brake far behind. Of failures of the triple valve to act we find fifteen reports, causing a very trifling delay to the trains. The air-pump is reported with cleven failures, and the driver's brake-valve has no failtures recorded against it. When we consider the enormous mileage of $15,505,447$ miles run by trains fitted with the Westinghouse automatic for the six months ending June 30 , we cannot help being astonished at the freedom from failure of the different parts, and the general efficiency of the apparatus.

Much has been written about the failure of the simple vacuum brake in the Penistone accident on the Manchestcr, Sheffield, and Lincolnshire Railway, the disaster being attributed by some to the brake failure alone. Certainly, had the train bcen fitted with the
Westinghouse automatic, the brake power on each vehicle would have remained intact, no matter how many couplings broke: but at the same time the fact seems to have been overlooked that the train had no permanent way to run on, since the engine broke up the chairs as it advanced, and the question remains, How would the train have been affected, having nearly all the wheels locked by the brake, and running over sleepers alone? Pcrhaps the train would not have travelled so far before going over the embankment; but we think the disaster would have been equally serious, each vehicle becoming detached by the sudden application of the brake, the couplings breaking on account of the violent jerks in passing over the sleepers, the curve tending to throw the vehicles over the embankment. As an example of the life-saving qualities of an automatic brakc in an accident, we think the Penistone disaster would have been a poor specimen.

The question of automatic versus simple brakes, both pressure and vacuum, is now fairly before the public, and the policy of the Board of Trade seems more apparent every day. It would not be wise on their part to enforce the adoption of any particular patent brake, for a better one may any day be discovered, but the Board may fairly insist that their conditions as to the qualities of any brake adopted by any Company should be complied with, and, if necessary, enforced by Act of Parliament.

\section{THE GALVANOMETER OF D'ARSONVAL AND DEPREZ}

CALVANOMETERS of innumerable kinds abound, and each form has some special merit which renders it useful for certain restricted services. The old astatic instrument of Nobili is still preferred by many to the more modern mirror galvanometer of Sir W. Thomson because it requircs no lamp, and can be used without darkening the room. The tangent galvanometer still holds its own in the testing-room for simple tests; and the lincman's detector is still indispensable on the score of its portability. For commercial purposes, where strong currents and steady potentials have to be measured, the ncwer ampere-meters and volt-meters have displaced the older forms of instrument. But still there is no best galvanometer of universal adaptability, even the Siemens "universal" galvanometer being too clumsy to meet with general favour.

For the purposes of the private laboratory a galvanometer is desired which shall be scnsitive, yet accurate in its indications, capable of being used for measuring currents of all kinds, weak and strong, and of measuring differences of potential from the thousandth of a volt to a thousand volts. It ought to be capable of being used in broad daylight ; of being rapidly read off ; and it ought also to be independent of external magnetic disturbances. The annoyances which arise from the last two causes when working with sensitive galvanometers are only too well known. The needle of the instrument once deflected continues to oscillate perhaps for half a minute, perhaps longer, causing vexatious delays, and when perhaps it has settled down at last to zero, some person in the next room moves a piece of iron-a poker, a penknife, or some other magnetic object-causing the zero of the instrument to change. An aperiodic dead-beat instrument, not subject to extcrnal magnetic forces, would be a boon indeed.

A galvanometer' which, without being absolutely perfect, goes very near to fulfilling these desirable conditions has lately been put into the hands of electricians by M. Carpentier, of Putris, successor to the wcll-known Ruhmkorff. It is the invention of M. Marcel Deprez as modified and improved by I)r. d'Arsonval. The many novel features which it presents would of themselves justify its description in the pases of NATURE; and the general excellence 